\title{
Digital PR technologies: establishing an interactive dialogue between public-political institutions and society
}

\author{
Yulia Lektorova ${ }^{1, *}$, Andrei Prudnikov ${ }^{1}$, and Vera Radosteva ${ }^{1}$ \\ ${ }^{1}$ Perm National Research Polytechnic University, 614990, 29 Komsomolsky ave., Perm, Russia
}

\begin{abstract}
The study presents the results of a sociological survey of Russian citizens' attitudes toward various forms of filing appeals to state (municipal) authorities. Based on the web content analysis of existing services for processing calls from the public on the Internet, the models of electronic monitoring of citizens' appeals are systematized: a special service for receiving and initial processing of citizens' appeals, created as a subdomain of the main site, a web portal as an independent Internet reception site and an auxiliary electronic resource reception of citizens' appeals, implemented on community sites in social networks.
\end{abstract}

\section{Digital-PR technologies as an element of strategic communications in the context of an interactive dialogue between public-political institutions and society}

Social-economic and political changes in the life of Russian society in the period of 19801990-s led to the formation of new institutions and practices of public administration, which formed the framework of the system of interaction between government and society. The monologue of the party-state apparatus with the population based on the methods of mass propaganda was replaced by a dialogue conducted through PR technologies in the conditions of relative ideological and political competition, pluralism of ideas, opinions and assessments. The transformation of the political course of the first post-perestroika years was later supplemented by further adjustments made to the system of political and communicative interaction between the government and society. At the present stage of development of the society electronic communication supported by official websites, blogs, social media accounts and messengers is the conditions for an effective dialogue.

As the telecommunication infrastructure develops and information technologies are introduced into the social-political sphere, a special virtual communication platform of power and society, resources supported by the Internet, is gradually being formed. Ideally, digital technologies in the system of public relations in the authorities are focused on a transparent dialogue: through their use, representatives of all branches of government become more accessible, their activities are more open. At the same time, such technologies act as a feedback tool: citizens ' attitude to certain social-political issues can be diagnosed

* Corresponding author: lektorova2015@yandex.ru 
by monitoring comments and posts on social networks, blogs, discussion tapes at information portals and websites. It is obvious that the communication between the authorities and the population, supported by Internet resources, is more focused on the functioning of the bilateral dialogue "in the open system" than the previous mechanisms of interaction [1].

The demand for digital technologies in the practice of public relations in government is explained by the trend of virtualization of social communication in general. According to Swedish scientists, a modern person checks updates on his / her gadget 150 times a day on average [2]. According to official statistics, in Russia there is an annual increase in the number of Internet users: 64 Russians applied to the global network for information per 100 people in 2013, in 2016 this figure reached 73 people [3], most of whom (71.5\%) were active users.

In the flow of virtual communication electronic dialogue between the authorities and society for more than twenty years of Runet history acquires sustainable practices: rules of political and communicative interaction in the "world wide web" and the strategy of behavior of key factors are approved. According to the official version, the share of the Russian population using the Internet for public and municipal services is $51.3 \%$ [4] (of the total population according to 2016). Taking into account the massive integration into the virtual landscape, digital-dialogue is an inevitable condition of modern PR practice in the state segment.

In Russian legislative practice, there are three main forms of citizens' appeals made in a written form, the form of an electronic document and an oral form at a personal reception. The text of the Federal law [5] establishes the right of residents to individual and collective appeal to the state power and local administration authorities. Consideration of proposals, applications or complaints of the population is free.

Today, residents of Russia are increasingly using electronic forms of appeals over the Internet. According to official statistics, the total number of appeals received in the name of the President of the Russian Federation in September 2017 decreased compared to the same period in 2016. At the same time there is an increase in the activity of the population on the Internet: out of 67593 appeals (data including appeals from foreign countries) 62,215\% were sent by means of electronic document circulation, $30,474 \%$ in writing and $7,311 \%$ orally [7].

\subsection{The attitude of modern society to the forms of citizens' appeals: the results of sociological monitoring}

The study attempted to determine the attitude of citizens to the various mechanisms and forms of submission of applications to the authorities. In the context of this research the results of sociological monitoring determine the prospects of online forms of work with citizens' appeals.

Questionnaire survey was chosen as a research method. To achieve this goal, the survey was conducted among residents of Perm and the Perm region. In accordance with the methodology of the study, respondents were asked to answer questions related to the presence in their lives of social problems and preferred forms of submission of appeals to state institutions. Among the types of surveys used were absentee (self-completion questionnaire) and face-to-face surveys, two survey sites on the platforma "Survio" and 'Google" were used additionally. The average value was derived from the results obtained on two sites.

The quota selection was used to justify the selection (sample with predefined values: young people, middle-aged people and pensioners). One-time, one-stage (quota selection from the General population) and heterogeneous (gender, socio-demographic, territorial 
criteria) were used among the sample types. The total sample consisted of 250 respondents. According to Rosstat, the number of residents of Perm in 2017 is 1041876 people.

In the framework of the sociological research, respondents were asked to determine the presence / absence of social and public problems in their lives. The results of the study indicated the relevance of the majority of Perm residents social and public problems-79\% of respondents answered "Yes".

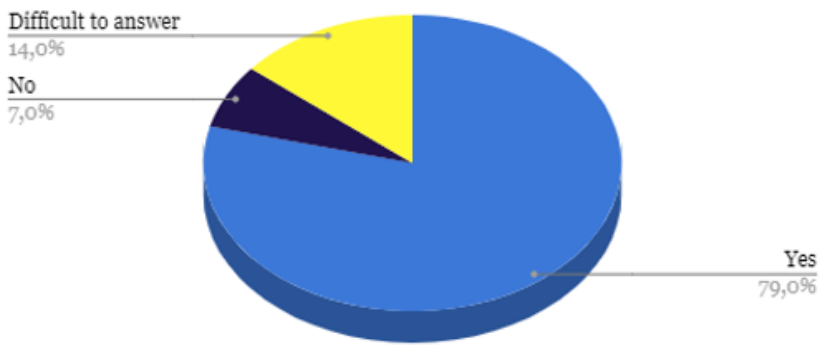

Fig. 1. The presence of social and public problems in the life of Perm residents.

The problems were detailed and the results demonstrated the priority of different life issues for Perm residents. Thus housing problems (56\%) and health services (48\%) maintain the highest figures for the city. Further the problems of social security $(37 \%)$, landscaping (24\%) and human rights violations (18\%) are located by frequency. Unemployment (16\%) and education (16\%) cause the least problems for city residents.

In an attempt to resolve social and public issues, Perm residents often rely on their own strength (78\%) and the help of close friends/relatives (56\%). $44 \%$ are ready to apply to the authorities for help. At the same time, $61 \%$ of the surveyed Perm citizens in different periods of life needed legal advice. Among the possible mechanisms for obtaining professional advice, respondents preferred electronic forms of citizens ' appeals:

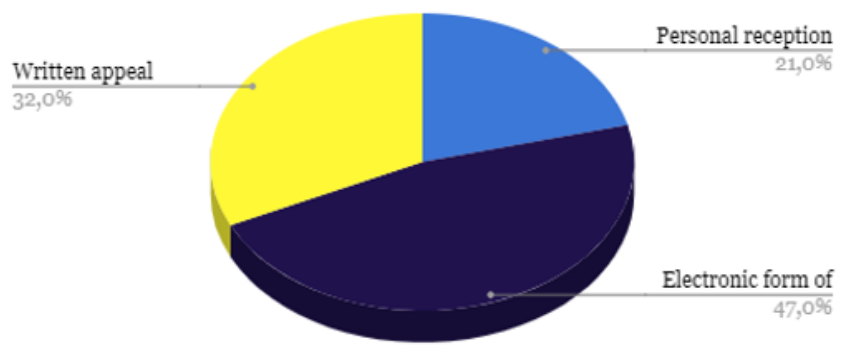

Fig. 2. Preferred forms of citizens' appeals among Perm residents.

The survey data show that the electronic form of citizens' appeals (47\%) and written statements $(32 \%)$ were the most preferred for Perm residents. Among the available electronic forms of citizens' appeals $59 \%$ of respondents estimated the possibilities of social networks: $31 \%$ of respondents are ready to use the "citizens 'appeals" tab on the authority official website and $27 \%$ of Perm citizens identified the Internet reception as the most convenient tool for submitting appeals. 
Sociological monitoring of citizens ' perception of electronic forms of interaction with the authorities concerning population appeals showed the interest and willingness of the society to virtual dialogue. Electronic practices of monitoring citizens ' appeals fit into the modern context of the use of public relations digital tools in government.

\section{Modern electronic monitoring models of citizen's appeals}

In Russian practice of monitoring and processing of information received in the form of electronic applications of citizens, it is possible to identify several emerging models. Firstly, it is a special service of reception and primary processing of citizens ' appeals, created on the basis of (as a subdomain of the main site) the official site of the authority (socio-political organization). Secondly, it is the web portal as an independent promo-site of a public reception, affiliated to a particular state or political organization. Thirdly is the official specialized portal for receiving and processing requests, which operates on the basis of GIS technologies. What instrument contributes to building the most effective work in the field of public relations in the context of state and public policy? The answer to this question should start with an analysis of the advantages and disadvantages of each of the models under consideration.

\subsection{Model 1. The service of processing citizens ' appeals is created as a subdomain of the official authority website.}

As an example, a special service of reception and processing citizens ' appeals, the affiliate portal of the President of Russia and the presidential Administration of the Russian Federation (http://letters.kremlin.ru), identified as the site of the office of the President working with references of citizens and organizations can be used. Among similar web resources a beta version of a specialized portal of the lower House of the Russian Parliament - "Reception of the State Duma" (https://priemnaya.parliament.gov.ru/) should be considered.

Both of these resources allow any citizen to send an e-mail message to the authorities, officials and elected persons, or to study the instruction (as well as to submit an application) on full-time, personal admission on a particular issue. At the same time both resources invite the visitor to select the addressee who will receive the complaint or any question before compiling the appeal and attaching the necessary electronic documents to it. In the case of the service letters.kremlin.ru the user faces a choice either to apply directly to the "electronic reception of the President of the Russian Federation" or entrust the consideration of his concerns to "electronic reception Administration of the President of the Russian Federation."

Similar alternatives are also offered by the website "Reception of the state Duma". Through the forms for submission of e-letters and appeals, the user in this case can apply either to the office of the Russian Parliament, or using the service "search for a Deputy", go to the tab of a particular parliamentarian, to whom the e-appeal will be sent. In both cases, users are not given either brief or detailed explanations which message addressee options are best chosen in a given case. It is also unclear how (and whether in principle) the choice made can influence the further way of consideration of the received electronic address.

In this case the option (which has to be done intuitively in many ways) rather complicates the visitor's task in terms of the basic needs of any average Internet user. The user wishes to get the necessary information through the use of an intuitive interface and navigation as quick and easy as possible.

There is one more minus of the analyzed model of communication with the user. There are too long and formalized instructions and explanations for how to make Internet 
requests, which can be perceived by the "average" applicant as a barrier to obtaining information or as a too complex mechanism for obtaining information.

Nevertheless, the resources under consideration have significant advantages. In particular on the portal they have an exchange of questions and answers of citizens with the official authorities of personal user accounts. Registration of the personal account allows to further receive the answer and to use these resources in the simplified mode. For example, the website of the presidential Administration of the Russian Federation indicates that in the "personal account» the author, after the authorization, is offered the possibility of obtaining a chronologically structured information about the progress and results of consideration, submitted through "my account" requests addressed to the President of the Russian Federation and presidential Administration of the Russian Federation"[7].

Among the potential strengths of this model of two-way communication through the "state-society "can also be attributed to the presence on the considered portals of headings" news"," reviews of appeals", which covers the progress of face - to-face receptions of citizens, the process of execution of orders, data in the framework of their implementation. However this is done more in the form of dry statistical information, which is uninformative for the end user concerning the information of the considered portals. It is obvious that only by changing the submission of this information and allowing citizens to monitor the execution of the most important and difficult orders, given as a result of a consideration of a particular appeal, it is possible to create users' interest in entering into a dialogue with the state who would like to do it, but hesitate for one reason or another.

\subsection{Model 2. The Internet - reception is a self-promotional website.}

Within the framework of this model, it seems appropriate to distinguish two quite different subtypes of the organization of sites for receiving and processing citizens ' appeals. The first subtype concerns the websites of separately existing public reception offices of large socio - political organizations, closely cooperating with the state. As an example, it is possible to use the official website of the Regional public reception Of the Chairman of the party "United Russia" D.A. Medvedev in the Perm region https://rop59.ru .

A distinctive feature of this portal is an introduction of service of electronic interaction with citizens-applicants directly on the separate site of the regional reception created at the socio-political organization. At the same time it is important to note that there is no single Federal portal for the Reception of the Chairman of the United Russia party. The only way to apply to the Central reception, as stated on the official website of the party,[8] is to come to the full-time reception at the strictly allotted hours at the specified address in Moscow. On this background it is particularly advantageous to look full-fledged regional website of the regional public reception (not tied to the Perm branch of the party, and functioning as a single portal to handle incoming requests) online counselling on frequently asked questions with the ability to appeal to deputies of all levels (from local and regional to Federal to the state Duma deputies and senators of the Federation Council), officials of the regional authorities and territorial divisions of Federal Executive authorities, as well as legal advisors and consultants specializing in dealing with housing and communal services.

At the same time, the applicant is given the opportunity to select not only the option of filling in the application through the proposed form, but also the option of ordering a "callback" or a call via skype. According to reports on the official website of the reception, such a form of consideration of citizens is practiced not only by regular reception employees, who in fact perform the functions of telephone operators-consultants and office workers in one person, but also by deputies and heads of of state bodies departments, in the rotation mode receiving citizens on private matters in person weekly. 
The advantages of the model of the autonomous site of the reception include the following factors:

1) a separate site allows placing a much greater amount of information about what questions and what recipients can be addressed to. At the same time, it can be categorized without creating navigation difficulties for users;

2) a separate site allows to place, except a form of an electronic message to a citizen, a lot of promotional materials (banners with slogans and counters, encouraging more actively to deal with questions and suggestions through the reception website, applicants feedback who received answers to questions or assistance in solving the problem/ implementation of public initiatives);

3) a separate site allows to present on the main page in a lively and accessible way the specific results of the consideration of citizens ' appeals, motivating applicants to actively use the platform of electronic reception to address certain issues.

Among the disadvantages of the service under consideration is the obvious one-sided information of applicants about the results of the work on the consideration of citizens ' issues by the staff of the reception and the deputies and officials they invite. In fact, the news tape of the portal provides not so much information about the performance of the reception as reporting on the detailed and intensive process of studying the tasks that citizens pose to the authorities. As a result, we see that the reception receives a significant amount of incoming requests from applicants, which are regularly reviewed, but we can not assess how quickly and effectively the actual and socially significant problems are solved, what support and development socially useful initiatives from below receive.

\subsection{Model 3. Portal of processing citizens' appeals, functioning on the basis of GIS technologies.}

The second subtype under this model is a mechanism for receiving and processing Internet requests based on GIS technologies. The specialized regional portals initiated by Russian regional administrations aimed at promoting the local power as the effective performer of orders and constantly arising inquiries of voters from local authorities give the ground for isolation of this type. According to this design, a scheme is being implemented, involving the creation within a single subject of the Federation of a model of joint management of urban and rural settlements by regional and municipal authorities, on the one hand, and local residents and their communities, on the other.

The most striking illustrations of this type of communication between the state and citizens-applicants can be considered a web resource "Moscow is our city of the mayor of Moscow S. S. Sobyanin" (http://gorod.mos.ru/) and created largely in his image and likeness the website "Manage together. Perm Krai development program" (http://permkrai.ru/program/). This site is located in the domain zone of the authorities of Perm krai (http://permkrai.ru ).

The uniformity of these portals is obvious. In both cases, we are talking about interactive electronic databases created on the basis of unified patterns of GIS technology. In short, these are electronic geographical maps of municipalities, where after registration any user can indicate specific problem points. When this information is submitted the problem is assumed to be promptly eliminated by local government and regional authorities, and the user receives a relevant report. It provides information on the prospects of resolving the issue, if it is not possible to reduce its relevance.

The reviewed websites are characterized in terms of image and political ones, are used as a mechanism of positioning regional heads in the framework of political competition in the electoral campaigns and maintain a high ranking in the period between elections. Thus, the portal "Moscow is Our City" was launched in 2011 in the capital in the midst of S. 
Sobyanin's election campaign for a mayor. In many ways, the creation of this website was a response to the launch of a similar web resource with the same functionality of "Rosyama". This site, created in 2011 by the team of the leader of the Russian non-system opposition A. Navalny, ("Rosyama" is positioned as the specialized and automated Internet service, operating on the basis of GIS technologies, and serves to send citizens to the traffic police and road services complaints about the condition of a paving in any point of Russia), on the contrary, was designed to demonstrate the inability of the Moscow authorities to quickly solve the problems of the population and was actively used by the opposition in the struggle for the post of the mayor of Moscow.

Together with a pronounced political and technological coloration, these websites are by no means purely agitation resources. These resources are multi-functional and large-scale in terms of coverage of potentially solved urban improvement problems through their use. GIS technologies are used as the main channel of communication with users in this case. As a result, the applicant can send an electronic appeal (attaching photos and videos, if necessary) to the regional and municipal authorities regarding a specific problem relating to urban improvement by clicking on a particular point on the map. Thus, the applicant is relieved of the need for long textual explanations. At the same time, the applicant has a more intuitive design of the interface of the Internet service for filing appeals.

Due to the marked simplicity and intuitive interface, such websites can be successfully positioned as fully effective Express services to address the problems of improvement of various settlements. It is beneficial to both the public and the authorities, able to use a mechanism for rapid and adequate solutions to the problems of the electorate as an evidence of its success and effectiveness. As a result, these websites, especially during electoral cycles, receive a much greater number of references in the media than similar sites designed to simplify communication between citizens and the authorities, examples of which we have given above. Accordingly, resources of this type have a much more serious potential for increasing user's traffic in the future.

Another inherent advantage of the model under consideration is that citizens ' activity is aggregated into socially useful initiatives and assistance to municipal and regional level administrators in monitoring the problems of landscaping and maintenance. In a number of municipalities of Russia positions of "street foot inspectors" whose activity is paid from the budget are entered. It is possible to assume that such format of interaction with citizens potentially gives the chance to save budgetary funds for implementation of the specified range of tasks about what $\mathrm{M}$. G. Reshetnikov reported in one of the interviews as the Minister of the Government of Moscow: "...the mayor can't visit each yard and check what has or hasn't really been done. And with the help of this website, we have essentially doubled the control, for example, for the improvement of yards. Residents check even more sites than our services. Such information is easier to process and issue a management decision - a penalty, a fine, the removal of defects" [9].

Due to the pronounced specialization of such websites there are appropriate restrictions, which can be attributed to the shortcomings of the model of communication. The possibility of filing appeals on topics, not included in the range of the moderators considered the portal, is excluded; personal requests and petitions are not allowed to submit.

On the basis of the material mentioned above, it can be concluded that the trend of virtualization of modern communication creates additional opportunities for political and communicative interaction between the government and society and meets the objectives of the state interests in the information sphere, focused on supporting democratic institutions and mechanisms of a civil society.

\section{References}


1. L. V. Azarova, V. A. Achkasova, Russian piarologiya-5: trends and drivers (Saint Petersburg state University of Economics, Saint Petersburg, 2017)

2. M. Umarov, PR in real time. Trends. Cases. Regulations. (Alpina Publisher, Moscow, 2017)

3. Monitoring of information society development in Russia (http://www.gks.ru/wps/wcm/connect/rosstat_main/rosstat/ru/statistics/science_and_in novations/it_technology)

4. Strategy for Information Society Development until 2030 approved (http://en.kremlin.ru/acts/news/54477)

5. Federal law No. 59-FZ of 02.025.2006 on the procedure for consideration of citizens' appeals of the Russian (http://www.consultant.ru/document/cons_doc_LAW_59999)

6. The information and statistical review of citizens' appeals, organizations and public associations addressed to the President of the Russian Federation considered in September 2017 (http://static.kremlin.ru/media/letters/digests/j4cHzEa8NDGMi4Au B3FTOPEKzNcAN2FA.pdf)

7. Presidential Directorate for Correspondence from Citizens and Organizations (http://letters.kremlin.ru/receptions/electronic/info)

8. Official website of the party "United Russia" (http://er.ru/reception/central-reception)

9. S. Volkova, The capital's officials are afraid of bad fame on the Internet more than their bosses (https://www.perm.kp.ru/daily/25859/2827004) 